\title{
Importance of Cardiopulmonary Exercise Testing amongst Subjects Recovering from COVID-19
}

\author{
Gianluigi Dorelli ${ }^{1}\left(\mathbb{D}\right.$, Michele Braggio ${ }^{1}\left(\mathbb{D}\right.$, Daniele Gabbiani ${ }^{2}$, Fabiana Busti ${ }^{2}{ }^{(D}$, Marco Caminati $^{3}(\mathbb{D}$, \\ Gianenrico Senna $^{3}$, Domenico Girelli ${ }^{2}\left(\mathbb{0}\right.$, Pierantonio Laveneziana ${ }^{4}$, Marcello Ferrari ${ }^{1}$, Giulia Sartori ${ }^{2,5}$, \\ Luca Dalle Carbonare ${ }^{1,2} \mathbb{D}$, Ernesto Crisafulli ${ }^{2,5, * \mathbb{C}}$ and on behalf of the RESPICOVID Study Investigators ${ }^{\dagger}$
}

1 School of Medicine in Sports and Exercise, University of Verona, 37134 Verona, Italy; gianluigi.dorelli@gmail.com (G.D.); michele.braggio@gmail.com (M.B.); marcello.ferrari@univr.it (M.F.); luca.dallecarbonare@univr.it (L.D.C.)

2 Department of Medicine, Section of Internal Medicine, University of Verona and Azienda Ospedaliera Universitaria Integrata of Verona, 37134 Verona, Italy; daniele.gabbiani@yahoo.com (D.G.); fabiana.busti@univr.it (F.B.); domenico.girelli@univr.it (D.G.); giulia.sartori.verona@gmail.com (G.S.)

3 Department of Medicine, Allergy and Clinical Immunology Section, University of Verona and Azienda Ospedaliera Universitaria Integrata of Verona, 37134 Verona, Italy; marco.caminati@univr.it (M.C.); gianenrico.senna@univr.it (G.S.)

4 INSERM, UMRS1158 Neurophysiologie Respiratoire Expérimentale et Clinique, AP-HP, Sorbonne Université, Groupe Hospitalier Pitié-Salpêtrière Charles Foix, Service des Explorations Fonctionnelles de la Respiration, de l'Exercice et de la Dyspnée du Département Médico-Universitaire «APPROCHES», 75013 Paris, France; pierantonio.laveneziana@aphp.fr

check for updates

Citation: Dorelli, G.; Braggio, M.; Gabbiani, D.; Busti, F.; Caminati, M.; Senna, G.; Girelli, D.; Laveneziana, P.; Ferrari, M.; Sartori, G.; et al. Importance of Cardiopulmonary Exercise Testing amongst Subjects Recovering from COVID-19.

Diagnostics 2021, 11, 507.

https://doi.org/10.3390/

diagnostics 11030507

Academic Editor: Lars C. Gormsen

Received: 21 January 2021

Accepted: 11 March 2021

Published: 12 March 2021

Publisher's Note: MDPI stays neutral with regard to jurisdictional claims in published maps and institutional affiliations.

Copyright: (c) 2021 by the authors. Licensee MDPI, Basel, Switzerland. This article is an open access article distributed under the terms and conditions of the Creative Commons Attribution (CC BY) license (https:/ / creativecommons.org/licenses/by/ $4.0 /)$.
5 Respiratory Medicine Unit, University of Verona and Azienda Ospedaliera Universitaria Integrata of Verona, 37134 Verona, Italy

* Correspondence: ernesto.crisafulli@univr.it

$\dagger$ Membership of the RESPICOVID study investigators is provided in Acknowledgments.

Abstract: The cardiopulmonary exercise test (CPET) provides an objective assessment of ventilatory limitation, related to the exercise minute ventilation $\left(\mathrm{V}_{\mathrm{E}}\right)$ coupled to carbon dioxide output $\left(\mathrm{V}_{\mathrm{CO} 2}\right)$ $\left(\mathrm{V}_{\mathrm{E}} / \mathrm{V}_{\mathrm{CO} 2}\right)$; high values of $\mathrm{V}_{\mathrm{E}} / \mathrm{V}_{\mathrm{CO} 2}$ slope define an exercise ventilatory inefficiency (EVin). In subjects recovered from hospitalised COVID-19, we explored the methodology of CPET in order to evaluate the presence of cardiopulmonary alterations. Our prospective study (RESPICOVID) has been proposed to evaluate pulmonary damage's clinical impact in post-COVID subjects. In a subgroup of subjects (RESPICOVID2) without baseline confounders, we performed the CPET. According to the $\mathrm{V}_{\mathrm{E}} / \mathrm{V}_{\mathrm{CO} 2}$ slope, subjects were divided into having EVin and exercise ventilatory efficiency (EVef). Data concerning general variables, hospitalisation, lung function, and gas-analysis were also collected. The RESPICOVID2 enrolled 28 subjects, of whom 8 (29\%) had EVin. As compared to subjects with EVef, subjects with EVin showed a reduction in heart rate (HR) recovery. $\mathrm{V}_{\mathrm{E}} / \mathrm{V}_{\mathrm{CO}}$ slope was inversely correlated with HR recovery; this correlation was confirmed in a subgroup of older, non-smoking male subjects, regardless of the presence of arterial hypertension. More than one-fourth of subjects recovered from hospitalised COVID-19 have EVin. The relationship between EVin and HR recovery may represent a novel hallmark of post-COVID cardiopulmonary alterations.

Keywords: cardiopulmonary exercise test; COVID-19; exercise ventilatory inefficiency; heart rate recovery; cardiovascular alterations

\section{Introduction}

Shortly after discharge, survivors of COVID-19 present lung function alterations with reduction in diffusion capacity for carbon monoxide (DLCO) [1] and severe impairments in physical function during activities of daily living [2]. Few data are available about a comprehensive evaluation of COVID-19 clinical alterations during a more extended period.

The cardiopulmonary exercise test (CPET) provides an objective assessment of exercise capacity, adding physiological aspects that limit the individual's performance [3]. In 
particular, the exercise minute ventilation $\left(\mathrm{V}_{\mathrm{E}}\right)$ relative to carbon dioxide output $\left(\mathrm{V}_{\mathrm{CO} 2}\right)$ $\left(\mathrm{V}_{\mathrm{E}} / \mathrm{V}_{\mathrm{CO} 2}\right)$ shows complementary information about ventilatory limitation and ventilatory control [4,5]. During incremental exercise, the relationship between $V_{\mathrm{E}}$ and $\mathrm{V}_{\mathrm{CO} 2}$ may be plotted on a $y$-axis $\left(\mathrm{V}_{\mathrm{E}}\right)$ and $x$-axis $\left(\mathrm{V}_{\mathrm{CO} 2}\right)$; the slope of this regression line $\left(\mathrm{V}_{\mathrm{E}} / \mathrm{V}_{\mathrm{CO} 2 \text { slope }}\right)$ may be considered an indicator of ventilatory efficiency [4,5]. Lower and upper limits of normal range of $\mathrm{V}_{\mathrm{E}} / \mathrm{V}_{\mathrm{CO} 2}$ slope are reported from approximately 21 to 31 [4,6,7]. High values of $\mathrm{V}_{\mathrm{E}} / \mathrm{V}_{\mathrm{CO} 2 \text { slope }}$ define an exercise ventilatory inefficiency (EVin) [4,5]; this pathophysiological feature may explain the out-of-proportion breathlessness of patients with chronic obstructive pulmonary disease (COPD) [5]. Smokers with normal spirometry but with low values of $\mathrm{DL}_{\mathrm{CO}}$ may have EVin [8].

In our pilot study, we explored the methodology of CPET to post-COVID subjects in order to evaluate the presence of cardiopulmonary alterations.

\section{Materials and Methods}

A dedicated outpatient clinic has been organised at our tertiary hospital enrolling all adult subjects previously hospitalised for interstitial pneumonia due to COVID-19, with or without respiratory failure. The prospective RESPICOVID study has been designed to evaluate the prevalence and the clinical impact of pulmonary damage in subjects recovered from COVID-19. In a subgroup of subjects (RESPICOVID2) a CPET has been performed. The study protocol was approved by the local Ethics Committee (no. 2785CESC), according to the Good Clinical Practice recommendations and the requirements of the Declaration of Helsinki. Written informed consent was obtained from all participants.

\subsection{Inclusion Criteria}

All consecutive patients discharged were considered.

\subsection{Exclusion Criteria}

The study has not considered subjects with the following criteria: (a) age $>65$ years; (b) all concomitant previous respiratory or non-respiratory diseases; (c) chronic respiratory failure or need for oxygen-therapy under exertion; (d) moderate obesity defined by a body mass index (BMI) $\geq 35 \mathrm{~kg} / \mathrm{m}^{2}$; (e) inability to perform functional tests; (f) inability to perform a CPET with a peak respiratory exchange ratio (RER) $<1.05$ (to exclude poor motivation). Among chronic diseases, only stable arterial hypertension was accepted.

\subsection{Measurements}

All measures were collected prospectively beginning on 17 July 2020, after more than five months from subjects' discharge (mean time 169 days, standard deviation (SD) 28 days). We recorded demographic and anthropometric variables, data concerning the hospitalisation, clinical symptoms, and gas-analysis.

Lung function and CPET procedures were performed according to international recommendations $[3,9]$. A flow-sensing spirometer connected to a computer for data analysis (Jaeger MasterScreen PFT System) was used to measure lung function. Forced vital capacity (FVC), forced expiratory volume in the first second $\left(\mathrm{FEV}_{1}\right)$, total lung capacity (TLC), and inspiratory capacity (IC) were recorded. $\mathrm{FEV}_{1} / \mathrm{FVC}$ ratio and IC/TLC ratio were taken as the index of airflow obstruction and resting hyperinflation, respectively. Diffusion capacity for carbon monoxide ( $\mathrm{DL}_{\mathrm{CO}}$ ) was measured by the single breath method. $\mathrm{FEV}_{1}, \mathrm{TLC}$, and $\mathrm{DL}_{\mathrm{CO}}$ were expressed as percentages of the predicted values [10,11]. For the CPET, according to the ATS/ACCP Statement [3], we used a cycle ergometer (Cosmed, Milan, Italy) with a ramp protocol of 10 to 25 watts increment every minute and based on the predicted peak power output, in order to achieve an exercise time between 8 and $12 \mathrm{~min}$. Subjects were asked to avoid caffeine, alcohol, cigarettes, and strenuous exercise $24 \mathrm{~h}$ before the day of testing; to eat a light breakfast; and to avoid eating for the $2 \mathrm{~h}$ before the test. Subjects suspended $\beta$-blockers before testing, but they could take their current antihypertensive therapies. During the test, subjects were asked to maintain a pedal frequency of 65 per minute 
and were continuously monitored [3]. Patients were continuously monitored with a 12-lead electrocardiogram (ECG) and a pulse oximeter; blood pressure was measured every two minutes. Stopping criteria consisted of symptoms, such as unsustainable dyspnoea, leg fatigue or chest pain, a significant ST-segment depression at ECG, or a drop in systolic blood pressure or oxygen saturation $\leq 84 \%$ [3]. Oxygen uptake $\left(\mathrm{V}_{\mathrm{O} 2}\right)$ at the peak was expressed in $\mathrm{mL} / \mathrm{kg} / \mathrm{min}$. The ventilatory response during exercise was expressed as a linear regression function by plotting minute ventilation $\left(\mathrm{V}_{\mathrm{E}}\right)$ against carbon dioxide production $\left(\mathrm{V}_{\mathrm{CO} 2}\right)$ obtained every $10 \mathrm{~s}$, excluding data above the ventilatory compensation point, and the slope $\left(\mathrm{V}_{\mathrm{E}} / \mathrm{V}_{\mathrm{CO} 2 \text { slope }}\right)$ and $\mathrm{Y}$-intercept $\left(\mathrm{V}_{\mathrm{E}} / \mathrm{V}_{\mathrm{CO} 2 \text { intercept }}\right)$ values were obtained from the regression line. We used the regression equation of $\mathrm{V}_{\mathrm{E}} / \mathrm{V}_{\mathrm{CO} 2}$ slope for healthy subjects, according to Sun et al. [6], considering three standard deviations as the upper limit. Then, we considered subjects having a normal range of $\mathrm{V}_{\mathrm{E}} / \mathrm{V}_{\mathrm{CO}}$ slope (exercise ventilatory efficiency-EVef) and subjects with over the upper limit of $\mathrm{V}_{\mathrm{E}} / \mathrm{V}_{\mathrm{CO} 2}$ slope $(\mathrm{EVin})$. The cardiovascular response to exercise was expressed by the oxygen pulse $\left(\mathrm{O}_{2}\right.$ pulse), the double product (DP) reserve, and the heart rate $(\mathrm{HR})$ recovery, considering the value of heart rate measured after $1 \mathrm{~min}$ of exercise stops. At the end of the exercise, dyspnoea and leg fatigue were measured by a Borg 6-20 perceived exertion rate (RPE) scale [12]. Reasons for considering a maximal test were (a) a plateau of the $\mathrm{V}_{\mathrm{O} 2}$ more than $20 \mathrm{~s}$; (b) a RER > 1.15; (c) a rate of perceived exertion $>18$ on the Borg RPE scale [3].

As a measure of physical tolerance, walking capacity was assessed by the 6 min walking distance (6MWD) and performed according to the recommended guidelines [13]; the better of two consecutive tests was considered for the analysis. The reference equation for healthy adults was also used [14].

The Italian version of the International Physical Activity Questionnaire (IPAQ) was administered to measure the physical activity of the subjects in the last seven days, deriving three levels of metabolic equivalent of task (METs): inactive, minimally active, and healthenhancing physical activity (HEPA) active [15].

A preliminary Shapiro-Wilk test was performed. Data are reported as percentages for categorical variables, as mean (SD) or median [first quartile; third quartile] for continuous variables with a normal or non-normal distribution. Categorical variables were compared by the $\chi 2$ test or the Fisher exact test, while continuous variables were assessed by the independent t-test or the non-parametric Mann-Whitney test. Pearson (r) and Spearman $(\rho)$ correlations have been carried out between parametric variables. The area under a receiver operating characteristic curve (AUC) measured the diagnostic discrimination property of significant predicting ventilatory inefficiency. All analyses were performed using IBM SPSS, version 17.0 (IBM Corp., Armonk, NY, USA), with $p$-values of $<0.05$ considered statistically significant.

\section{Results}

The RESPICOVID study enrolled 130 subjects, but according to the selective criteria for the RESPICOVID2, defined to avoid baseline bias influencing the ventilatory response to exercise, we performed the CPET in 28 subjects. All subjects performed a maximal exercise test, and 8 out of $28(29 \%)$ had EVin. As compared to subjects with EVef, subjects with EVin showed a reduction in $\mathrm{HR}$ recovery and $\mathrm{V}_{\mathrm{E}} / \mathrm{V}_{\mathrm{CO}}$ intercept, with an increase by definition of the $V_{E} / V_{C O}$ slope and vigorous METs (Table 1 ). $V_{E} / V_{C O}$ slope was inversely correlated with HR recovery $(\mathrm{r}-0.537, p=0.003)$ (Figure 1$)$; this correlation was confirmed in a subgroup of older subjects (age $>55 \mathrm{y}, \mathrm{N}=14, \rho-0.611, p=0.020)$, males $(\mathrm{N}=22$, $\mathrm{r}-0.543, p=0.009)$, non-smokers $(\mathrm{N}=19, \mathrm{r}-0.611, p=0.005)$, regardless of the presence of arterial hypertension (yes, $\mathrm{N}=9, \mathrm{r}-0.669, p=0.049$; no, $\mathrm{N}=19, \mathrm{r}-0.487, p=0.034$ ). 
Table 1. General and CPET-related variables.

\begin{tabular}{|c|c|c|c|c|}
\hline Variables & $\begin{array}{l}\text { All Subjects } \\
\quad N=28\end{array}$ & $\begin{array}{l}\text { Subjects with EVef } \\
\qquad \mathbf{N}=\mathbf{2 0}\end{array}$ & $\begin{array}{l}\text { Subjects with EVin } \\
\qquad N=8\end{array}$ & $p$-Value \\
\hline Age, $y$ & $55.3[52.3 ; 61.9]$ & $55.1[53.6 ; 59.2]$ & $58.4[48.7 ; 63.7]$ & 0.576 \\
\hline Male, n (\%) & $22(79)$ & $15(75)$ & $7(87)$ & 0.640 \\
\hline BMI, $\mathrm{kg} / \mathrm{m}^{2}$ & $25.9 \pm 3.4$ & $25.8 \pm 3.2$ & $26.2 \pm 4.1$ & 0.765 \\
\hline FFMI, $\mathrm{kg} / \mathrm{m}^{2}$ & $19 \pm 2.2$ & $19 \pm 2.4$ & $18.9 \pm 1.9$ & 0.907 \\
\hline $\begin{array}{c}\text { Smoking habit, no/current or } \\
\text { former, } \mathrm{n}(\%)\end{array}$ & $19(68) / 9(32)$ & $13(65) / 7(35)$ & $6(75) / 2(25)$ & $>0.999$ \\
\hline Arterial hypertension, yes, n (\%) & $9(32)$ & $6(30)$ & $3(37)$ & $>0.999$ \\
\hline $\mathrm{FEV}_{1}, \%$ pred. & $118.1 \pm 13.6$ & $118.9 \pm 14$ & $116.1 \pm 13.1$ & 0.629 \\
\hline $\mathrm{FEV}_{1} / \mathrm{FVC}, \%$ & $101 \pm 6.1$ & $101.3 \pm 6.5$ & $100.2 \pm 5.6$ & 0.679 \\
\hline TLC, \% predicted & $104.2 \pm 12$ & $105.6 \pm 13$ & $100.6 \pm 8.8$ & 0.333 \\
\hline IC/TLC at rest & $0.50 \pm 0.08$ & $0.49 \pm 0.09$ & $0.51 \pm 0.06$ & 0.649 \\
\hline $\mathrm{DL}_{\mathrm{CO}}, \%$ predicted & $89.9 \pm 13.5$ & $90.2 \pm 13.9$ & $89.4 \pm 13.3$ & 0.888 \\
\hline $\mathrm{PaO}_{2} / \mathrm{FiO}_{2}$ & $484.6 \pm 37.6$ & $477.7 \pm 40.0$ & $500 \pm 27.7$ & 0.169 \\
\hline $\mathrm{PaCO}_{2}, \mathrm{mmHg}$ & $38.2 \pm 3$ & $38.4 \pm 2.6$ & $37.8 \pm 3.9$ & 0.699 \\
\hline $6 \mathrm{MWD}$, meters & $604.5 \pm 67.1$ & $598.2 \pm 56.1$ & $620.4 \pm 91.9$ & 0.440 \\
\hline $6 \mathrm{MWD}, \%$ predicted & $103 \pm 15.2$ & $101.8 \pm 15.4$ & $106.2 \pm 15.1$ & 0.502 \\
\hline $\begin{array}{c}\text { IPAQ (inactive, minimally active, } \\
\text { HEPA active), } \mathrm{n}(\%)\end{array}$ & $4(14) / 15(54) / 9(32)$ & $4(20) / 12(60) / 4(20)$ & $0(0) / 3(37) / 5(63)$ & 0.101 \\
\hline METs, vigorous & $0[0 ; 1320]$ & $0[0 ; 420]$ & $1520[120 ; 6120]$ & 0.018 \\
\hline METs, total & $1912.5[1015.5 ; 3410.2]$ & $1372[838.5 ; 2497]$ & $2805[1698.7 ; 10,865.5]$ & 0.053 \\
\hline Workload, watts & $187.7 \pm 64$ & $181.7 \pm 56$ & $202.7 \pm 83.4$ & 0.444 \\
\hline RER & $1.19[1.11 ; 1.25]$ & $1.20[1.13 ; 1.27]$ & $1.12[1.10 ; 1.20]$ & 0.062 \\
\hline $\mathrm{V}_{\mathrm{O} 2}$ at peak, $\mathrm{mL} / \mathrm{kg} / \mathrm{min}$ & $29.2 \pm 8.3$ & $27.6 \pm 5.2$ & $32.9 \pm 13.1$ & 0.137 \\
\hline $\mathrm{V}_{\mathrm{O} 2}$ at $\mathrm{AT}, \mathrm{mL} / \mathrm{kg} / \mathrm{min}$ & $17.6[15.9 ; 22.4]$ & $17.6[16.2 ; 20.4]$ & $20[13.5 ; 29.7]$ & 0.684 \\
\hline $\mathrm{O}_{2}$ pulse at rest, $\mathrm{mL} / \mathrm{beat} / \mathrm{min}$ & $7.3[5.8 ; 7.8]$ & $7.5[6.9 ; 7.9]$ & $6.2[5.4 ; 7.5]$ & 0.169 \\
\hline $\mathrm{O}_{2}$ pulse at peak, $\mathrm{mL} /$ beat $/ \mathrm{min}$ & $14.5 \pm 3.9$ & $13.8 \pm 3.8$ & $16.1 \pm 4$ & 0.168 \\
\hline $\mathrm{PET}_{\mathrm{CO} 2}$ change ${ }^{1}$ & $3.1 \pm 4.4$ & $3.7 \pm 4.7$ & $1.5 \pm 3.6$ & 0.235 \\
\hline $\mathrm{V}_{\mathrm{E}}$ at rest & $16.9 \pm 4.1$ & $16.6 \pm 4.4$ & $17.8 \pm 3.2$ & 0.470 \\
\hline$V_{E}$ at peak & $95.2 \pm 33.4$ & $89.2 \pm 27.3$ & $110.4 \pm 43.9$ & 0.131 \\
\hline $\mathrm{RR}$ at rest, bpm & $15.9 \pm 3.5$ & $15.7 \pm 3.8$ & $16.5 \pm 2.8$ & 0.637 \\
\hline RR at peak, bpm & $36.4 \pm 8.9$ & $34.4 \pm 7.4$ & $41.4 \pm 10.8$ & 0.057 \\
\hline $\mathrm{V}_{\mathrm{O} 2} /$ Watts, $\mathrm{mL} / \mathrm{min} /$ watts & $11.8[11.5 ; 12.6]$ & $11.8[11.4 ; 12.3]$ & $12.2[11.6 ; 13.9]$ & 0.263 \\
\hline $\mathrm{V}_{\mathrm{E}} / \mathrm{V}_{\mathrm{CO} 2 \text { slope }}$ & $27.7 \pm 3.9$ & $25.6 \pm 2.3$ & $32.9 \pm 1.5$ & $<0.001$ \\
\hline $\mathrm{V}_{\mathrm{E}} / \mathrm{V}_{\mathrm{CO} 2}$ at $\mathrm{AT}$ & $28.9 \pm 2.9$ & $28.2 \pm 2.7$ & $30.5 \pm 3$ & 0.066 \\
\hline $\mathrm{V}_{\mathrm{E}} / \mathrm{V}_{\mathrm{CO} 2 \text { intercept }}$ & $2.35[0.12 ; 5.37]$ & $3.65[1.75 ; 5.87]$ & $-1.10[-3.52 ; 0.57]$ & $<0.001$ \\
\hline $\mathrm{HR} / \mathrm{V}_{\mathrm{O} 2}$ slope, $\mathrm{L}^{-1}$ & $44.5[38.2 ; 70]$ & $47.2[39.8 ; 74.9]$ & $37.2[34.4 ; 59.1]$ & 0.060 \\
\hline Brething reserve, $\%$ & $36.5 \pm 14.7$ & $39.8 \pm 13$ & $28.1 \pm 16.3$ & 0.054 \\
\hline $\mathrm{V}_{\mathrm{D}} / \mathrm{V}_{\mathrm{T}}$ & $0.26 \pm 0.02$ & $0.26 \pm 0.02$ & $0.27 \pm 0.02$ & 0.151 \\
\hline $\mathrm{SBP}$ at rest, $\mathrm{mmHg}$ & $120[115 ; 125]$ & $120[116.2 ; 125]$ & $120[111.2 ; 125]$ & 0.853 \\
\hline SBP at peak, $\mathrm{mmHg}$ & $183.7 \pm 18.4$ & $185.7 \pm 19.1$ & $178.7 \pm 16.4$ & 0.373 \\
\hline $\mathrm{DBP}$ at rest, $\mathrm{mmHg}$ & $80[70 ; 80]$ & $80[70 ; 83.7]$ & $80[70 ; 80]$ & 0.625 \\
\hline DBP at peak, $\mathrm{mmHg}$ & $95.4 \pm 10.3$ & $94.5 \pm 9.9$ & $97.5 \pm 11.3$ & 0.495 \\
\hline $\mathrm{HR}$ at rest, beats $/ \mathrm{min}$ & $69.7 \pm 8.9$ & $70.1 \pm 10.1$ & $68.9 \pm 5.2$ & 0.749 \\
\hline HR at peak, beats/min & $156.6 \pm 18.7$ & $158.4 \pm 17.6$ & $152.1 \pm 21.7$ & 0.429 \\
\hline HR recovery, beats/min & $22.4 \pm 7$ & $24.4 \pm 5.8$ & $17.5 \pm 7.6$ & 0.015 \\
\hline DP reserve & $21060[16,515 ; 22,013]$ & $21030[17,647 ; 22,445]$ & $21,060[12,630 ; 21,952]$ & 0.647 \\
\hline $\mathrm{RPE}_{\text {dyspnea }}$, score & $16.2 \pm 2.6$ & $16 \pm 2.4$ & $16.8 \pm 3$ & 0.430 \\
\hline$R P E_{\text {fatigue, }}$ score & $17.5[16.2 ; 19]$ & $17.5[16.2 ; 19]$ & $18[15.5 ; 19.7]$ & 0.796 \\
\hline
\end{tabular}


Table 1. Cont.

\begin{tabular}{|c|c|c|c|c|}
\hline Variables & $\begin{array}{l}\text { All Subjects } \\
\quad \mathrm{N}=\mathbf{2 8}\end{array}$ & $\begin{array}{l}\text { Subjects with EVef } \\
\qquad N=20\end{array}$ & $\begin{array}{l}\text { Subjects with EVin } \\
\qquad \mathrm{N}=8\end{array}$ & $p$-Value \\
\hline \multicolumn{5}{|c|}{ Variables related to COVID-19 hospitalisation } \\
\hline $\mathrm{PaO}_{2} / \mathrm{FiO}_{2}{ }^{2} \leq 300, \mathrm{n}(\%)$ & $13(46)$ & $9(45)$ & $4(50)$ & $>0.999$ \\
\hline ICU / medical ward ${ }^{3}, \mathrm{n}(\%)$ & $5(18) / 23(82)$ & $2(10) / 18(90)$ & $3(37) / 5(63)$ & 0.123 \\
\hline Length of stay, $\mathrm{d}$ & $5.9[4.2 ; 10.5]$ & $5.9[4.2 ; 9.7]$ & $5.5[3.6 ; 21.9]$ & 0.779 \\
\hline Pulmonary embolism, n (\%) & $2(7.1)$ & $1(5)$ & $1(12.5)$ & 0.497 \\
\hline Oxygen-therapy, n (\%) & $16(57)$ & $10(50)$ & $6(75)$ & 0.401 \\
\hline Ventilatory support ${ }^{4}, \mathrm{n}(\%)$ & $10(36)$ & $6(30)$ & $4(50)$ & 0.400 \\
\hline Lopinavir/ritonavir, n (\%) & $22(79)$ & $16(80)$ & $6(75)$ & $>0.999$ \\
\hline Hydroxychloroquine, $\mathrm{n}(\%)$ & $26(93)$ & $18(90)$ & $8(100)$ & $>0.999$ \\
\hline Antibiotics, n (\%) & $9(32)$ & $7(35)$ & $2(25)$ & $>0.999$ \\
\hline Tocilizumab, n (\%) & $8(29)$ & $5(25)$ & $3(37)$ & 0.651 \\
\hline Steroids, n (\%) & $13(46)$ & $8(40)$ & $5(62)$ & 0.410 \\
\hline Prophylactic LMWH, n (\%) & $8(29)$ & $6(30)$ & $2(25)$ & $>0.999$ \\
\hline
\end{tabular}

Data are shown as the number of subjects (\%), means \pm SD or medians [first quartile; third quartile]. In bold, significant variables. Abbreviations: EVef and EVin define exercise ventilatory efficiency and inefficiency, respectively; BMI, body mass index; FFMI, fat-free mass index, calculated as FFM/height squared; $\mathrm{FEV}_{1}$, forced expiratory volume at 1st second; FVC, forced vital capacity; TLC, total lung capacity; IC, inspiratory capacity; $\mathrm{DL} C$, diffusion capacity for carbon monoxide; $\mathrm{PaO}_{2}$, arterial partial oxygen pressure; $\mathrm{FiO}_{2}$, fraction of inspired oxygen; $\mathrm{PaCO}_{2}$, arterial partial carbon dioxide pressure; 6MWD, 6-min walked distance; IPAQ, international physical activity questionnaire; HEPA, health-enhancing physical activity; METs, metabolic equivalent of task; RER, respiratory exchange ratio; $V_{\mathrm{O} 2}$, oxygen uptake; $\mathrm{PET}_{\mathrm{CO} 2}$, end-tidal pressure of $\mathrm{CO}_{2} ; \mathrm{V}_{\mathrm{E}}$, minute ventilation; $\mathrm{RR}$, respiratory rate; $\mathrm{V}_{\mathrm{E}} / \mathrm{V}_{\mathrm{CO} 2 \text { slope, }}$, the slope of $\mathrm{V}_{\mathrm{E}}$ to carbon dioxide output- $\mathrm{V}_{\mathrm{CO} 2}$ ratio; $\mathrm{AT}$, anaerobic threshold; $\mathrm{V}_{\mathrm{E}} / \mathrm{V}_{\mathrm{CO} 2}$ intercept, point of intercept of $\mathrm{V}_{\mathrm{E}}$ to carbon dioxide output $-\mathrm{V}_{\mathrm{CO} 2}$ ratio; $\mathrm{HR}$, heart rate; $\mathrm{V}_{\mathrm{D}}$, dead space; $\mathrm{V}_{\mathrm{T}}$, tidal volume; $\mathrm{SBP}$ and $\mathrm{DBP}$, systolic and diastolic blood pressure, respectively; DP, double product; RPE, rate of perceived exertion; ICU, intensive care unit. ${ }^{1}$ calculated as peak $\mathrm{PET}_{\mathrm{CO} 2}$ minus at rest $\mathrm{PET}_{\mathrm{CO} 2}{ }^{2}$ at hospital admission; ${ }^{3}$ unit of admission; 4 include subjects treated with continuous positive airway pressure (CPAP) and pressure support ventilation (PSV).

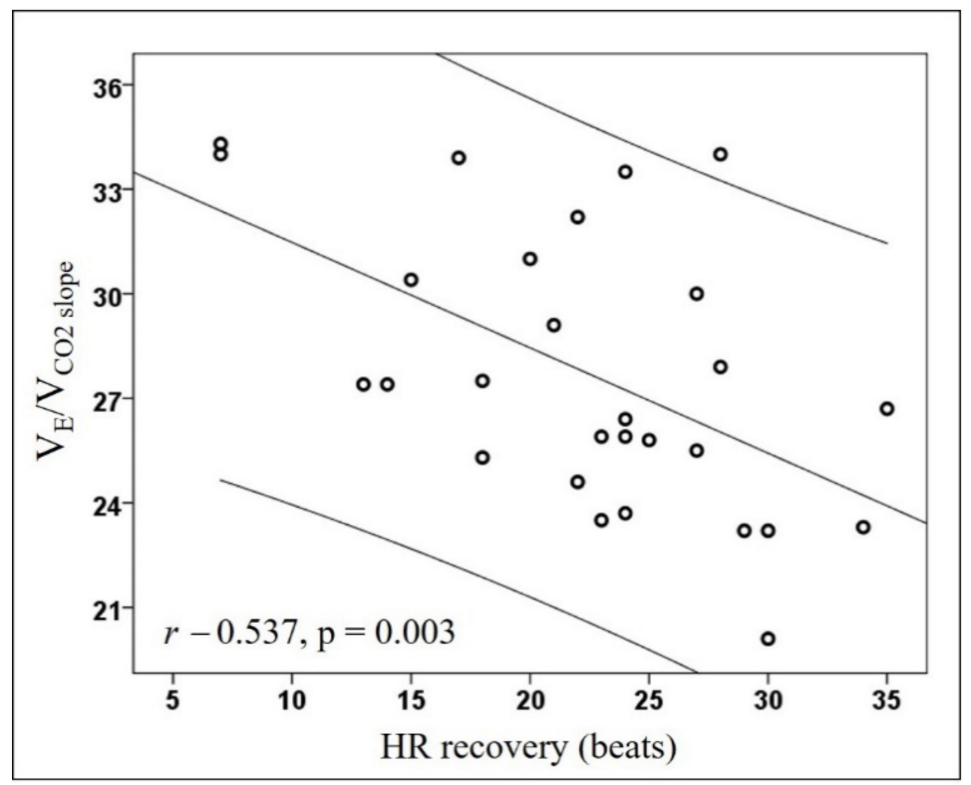

Figure 1. Scatterplot between $\mathrm{V}_{\mathrm{E}} / \mathrm{V}_{\mathrm{CO} 2}$ slope and $\mathrm{HR}$ recovery. Lines represent the regression with the $95 \%$ confidence intervals. Abbreviations: $\mathrm{V}_{\mathrm{E}} / \mathrm{V}_{\mathrm{CO} 2}$ slope represents the slope of minute ventilation $-\mathrm{V}_{\mathrm{E}}$ to carbon dioxide output- $\mathrm{V}_{\mathrm{CO} 2}$ ratio; $\mathrm{HR}$, heart rate.

The accuracy analysis of $\mathrm{HR}$ recovery showed a significant predictive discrimination (AUC, 0.767; standard error, $0.10 ; 95 \%$ confidence interval, 0.568 to $0.966 ; p=0.028$ ) with the best cutoff of 22 beats / minute ( 0.750 and 0.727 in the sensitivity and specificity evaluation) (Figure 2). 


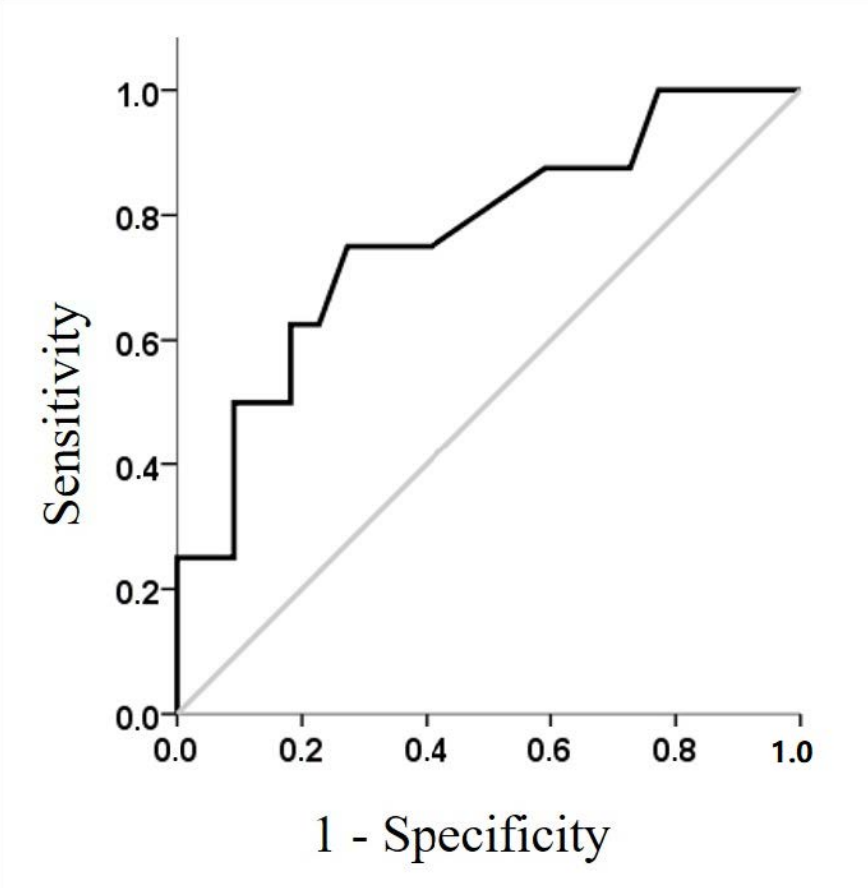

Figure 2. Receiver operating curve of HR recovery, performed on subjects with ventilatory inefficiency as test variable. Gray line represents a diagonal of reference.

Subjects with arterial hypertension were treated with ACE inhibitors $(\mathrm{N}=5,18 \%)$, $\beta$-blockers $(\mathrm{N}=4,14 \%)$, and $\mathrm{Ca}^{2+}$ antagonist $(\mathrm{N}=3,11 \%)$ with no differences between subjects with EVef and EVin.

\section{Discussion}

Our pilot study is the first evaluating, in survivors of COVID-19 pneumonia, the role of CPET variables during an extended follow-up after hospital discharge. Although our considered subjects had a normal lung function and a preserved maximal exercise capacity, surprisingly, more than one-fourth had an EVin, which is a determinant of HR recovery, especially older male non-smokers, regardless of the presence of arterial hypertension.

In smokers with normal spirometry but low values of $\mathrm{DL}_{\mathrm{CO}}$, EV in may be present [8] as well as [8] an impaired peripheral endothelial function [16]. In the context of alveolarcapillary membrane damage, decrements in $\mathrm{DL}_{\mathrm{CO}}$ may be more likely related to pulmonary microvascular abnormalities than impaired gas distribution [8]. We may hypothesise a similar mechanism in our post-COVID subjects, in which we observe five months from discharge a selective lung function impairment in $\mathrm{DL}_{\mathrm{CO}}$ reduction.

Ventilatory inefficiency in the healthy population is not a common occurrence. The normal upper limit of $\mathrm{V}_{\mathrm{E}} / \mathrm{V}_{\mathrm{CO} 2}$ slope is 31 [6,7]. Variables related to age and sex [6,17], such as chronic pulmonary and cardiovascular conditions, may influence the exercise ventilatory efficiency [3,4]; however, there is no concrete evidence that the fitness level has an impact on exercise ventilation $[18,19]$. In addition, regular endurance training may improve exercise ventilatory efficiency (potentially with a reduction in $\mathrm{V}_{\mathrm{E}} / \mathrm{V}_{\mathrm{CO} 2 \text { slope }}$ ) by reducing peripheral chemoreceptor sensitivity [18]. In our sample, subjects having EVin had a coexisting presence of higher values of $6 \mathrm{MWD}$, workload, and $\mathrm{V}_{\mathrm{O} 2}$ at peak, signs of a higher aerobic capacity. The levels of vigorous weekly METs were higher compared to subjects with EVef; however, this was not correlated to $\mathrm{V}_{\mathrm{E}} / \mathrm{V}_{\mathrm{CO} 2 \text { slope }}$ or $\mathrm{HR}$ recovery (data not shown). Interestingly, ventilatory efficiency is not related to residual lung function limitations and specific treatment during the COVID-19 hospitalisation. Although speculative, our findings of exercise ventilatory alterations in post-hospitalised subjects, evaluated without baseline bias, seems to be specific and COVID-related. 
HR recovery represents a marker of cardiac autonomic dysfunction and a predictor of mortality in adults without heart disease history [20]. In COPD patients, HR recovery is associated with endothelial dysfunction, representing peripheral impairment [21]. Moreover, EVin in COPD is a predictor of the delay of HR recovery [22]. Although our post-COVID survivors do not have an airways obstruction as in COPD, recent reports highlighted frequent extrapulmonary manifestations, especially involving the cardiovascular system (myocardial dysfunction, arrhythmia, and acute coronary syndromes), attributed to virus-mediated endothelial-cell damage [23]. Our findings on EVin and HR recovery could therefore represent a novel hallmark of post-COVID cardiopulmonary alterations. In these subjects, also with low cardiovascular risk (non-smokers without arterial hypertension), an in-depth assessment of exercise-induced ventilatory and cardiovascular parameters by CPET allows the identification (or monitoring) of early specific alterations. Further studies are needed to evaluate the progressive persistence and the prognostic role of these alterations.

As a limitation, we acknowledge the small number of subjects included, related to selective criteria considering younger subjects without previous diseases. Moreover, we lack data concerning the residual organic pulmonary damage (by lung ultrasound or thorax computed tomography scan) with indirect signs of pulmonary hypertension (by echocardiography).

\section{Conclusions}

More than one-fourth of post-COVID subjects present an exercise ventilatory inefficiency related to lower heart rate recovery; this aspect may be a sign of systemic alterations present in these subjects. Further studies in a very large cohort of subjects need to confirm our finding. In the future, it may be interesting to apply the methodology of CPET in elderly patients with or without coexisting diseases to evaluate the impact of COVID-19 on single chronic conditions.

We suggest CPET as a potentially useful tool for identifying ventilatory and cardiovascular alterations in subjects recovered from COVID-19. Moreover, CPET may be useful as a monitoring system for exercise capacity and cardio-ventilatory limitations in subjects admitted to a rehabilitation program.

Author Contributions: Conception and design of the study: G.D., D.G., P.L., E.C.; Acquisition, analysis, or interpretation of data: G.D., M.B., D.G., F.B., M.C., G.S. (Giulia Sartori); Drafting the work or revising it critically for important intellectual content: G.D., G.S. (Gianenrico Senna), D.G., P.L., M.F., L.D.C., E.C.; Approval of the final version of the manuscript: E.C. All authors have read and agreed to the published version of the manuscript.

Funding: This work was supported by a grant from the Cariverona Foundation (ENACT project).

Institutional Review Board Statement: The study was conducted according to the guidelines of the Declaration of Helsinki, and approved by the local Ethics Committee of Verona and Rovigo (protocol code no. 2785CESC, approval date 10 June 2020).

Informed Consent Statement: Informed consent was obtained from all subjects involved in the study.

Data Availability Statement: The data presented in this study are available on request from the corresponding author.

Acknowledgments: We are indebted to all medical and nursing colleagues for their assistance and cooperation in this study. The RESPICOVID study investigators are: Ernesto Crisafulli (Principal Investigator) and in alphabetical order Maria Chiara Ambrosetti, Marco Bodini, Francesco Bordin, Silvia Bozzetti, Michele Braggio, Fabiana Busti, Marco Caminati, Luca Dalle Carbonare, Gianluigi Dorelli, Angela Federico, Marcello Ferrari, Sergio Ferrari, Armando Fiore, Daniele Gabbiani, Domenico Girelli, Lucia Guidolin, Elettra Libener, Andrea Lobba, Giulia Magnani, Giancarlo Mansueto, Elisa Mantovani, Giacomo Marchi, Sara Mariotto, Alessio Maroccia, Claudio Micheletto, Francesca Nalin, Laura Sagramoni, Giulia Sartori, Gianenrico Senna, Francesca Stefani, Stefano Tamburin, Virginia Trevisan, Rachele Vaia, Maria Teresa Valenti, Alice Vianello, Alessandro Vignola, Donato Zipeto from the University of Verona and Azienda Ospedaliera Universitaria Integrata of Verona, Verona, Italy. 
Conflicts of Interest: The authors declare no conflict of interest. The funders had no role in the design of the study; in the collection, analyses, or interpretation of data; in the writing of the manuscript, or in the decision to publish the results.

\section{References}

1. Mo, X.; Jian, W.; Su, Z.; Chen, M.; Peng, H.; Peng, P.; Lei, C.; Chen, R.; Zhong, N.; Li, S. Abnormal pulmonary function in COVID-19 patients at time of hospital discharge. Eur. Respir. J. 2020, 55, 2001217. [CrossRef] [PubMed]

2. Belli, S.; Balbi, B.; Prince, I.; Cattaneo, D.; Masocco, F.; Zaccaria, S.; Bertalli, L.; Cattini, F.; Lomazzo, A.; Negro, F.D.; et al. Low physical functioning and impaired performance of activities of daily life in COVID-19 patients who survived hospitalisation. Eur. Respir. J. 2020, 56, 2002096. [CrossRef]

3. Society, A.T. American College of Chest Physicians ATS/ACCP Statement on Cardiopulmonary Exercise Testing. Am. J. Respir. Crit. Care Med. 2003, 167, 211-277. [CrossRef]

4. Phillips, D.B.; Collins, S.É.; Stickland, M.K. Measurement and Interpretation of Exercise Ventilatory Efficiency. Front. Physiol. 2020, 11, 659. [CrossRef]

5. Neder, J.A.; Berton, D.C.; Arbex, F.F.; Alencar, M.C.; Rocha, A.; Sperandio, P.A.; Palange, P.; O’Donnell, D.E. Physiological and clinical relevance of exercise ventilatory efficiency in COPD. Eur. Respir. J. 2017, 49, 1602036. [CrossRef] [PubMed]

6. Sun, X.-G.; Hansen, J.E.; Garatachea, N.; Storer, T.W.; Wasserman, K. Ventilatory Efficiency during Exercise in Healthy Subjects. Am. J. Respir. Crit. Care Med. 2002, 166, 1443-1448. [CrossRef]

7. Naeije, R.; Faoro, V. The great breathlessness of cardiopulmonary diseases. Eur. Respir. J. 2018, 51, 1702517. [CrossRef]

8. Barbosa, G.W.; Neder, J.A.; Utida, K.; O’Donnell, D.E.; Müller, P.D.T. Impaired exercise ventilatory efficiency in smokers with low transfer factor but normal spirometry. Eur. Respir. J. 2017, 49, 1602511. [CrossRef] [PubMed]

9. Miller, M.R.; Hankinson, J.; Brusasco, V.; Burgos, F.; Casaburi, R.; Coates, A.; Crapo, R.; Enright, P.; Van Der Grinten, C.P.M.; Gustafsson, P.; et al. Standardisation of spirometry. Eur. Respir. J. 2005, 26, 319-338. [CrossRef]

10. Quanyer, P.H.; Tammeling, G.J.; Cotes, J.E.; Pedersen, O.F.; Peslin, R.; Yernault, J.C. Lung volumes and forced ventilatory flows. Report Working Party Standardization of Lung Function Tests, European Community for Steel and Coal. Official Statement of the European Respiratory Society. Eur. Respir. J. Suppl. 1993, 16, 5-40.

11. Cotes, J.E.; Chinn, D.J.; Quanjer, P.H.; Roca, J.; Yernault, J.C. Standardisation of the measurement of transfer factor (diffusing capacity). Report Working Party Standardization of Lung Function Tests, European Community for Steel and Coal. Official Statement of the European Respiratory Society. Eur. Respir. J. Suppl. 1993, 16, 41-52.

12. A Borg, G. Psychophysical bases of perceived exertion. Med. Sci. Sports Exerc. 1982, 14, 377-381. [CrossRef] [PubMed]

13. American Thoracic Society Committee on Proficiency Standards for Clinical Pulmonary Function Laboratories. American Thoracic Society statement: Guidelines for the six-minute walk test. Am. J. Respir. Crit. Care Med. 2002, 166, 111-117. [CrossRef] [PubMed]

14. Enright, P.L.; Sherrill, D.L. Reference equations for the six-minute walk in healthy adults. Am. J. Respir. Crit. Care Med. 1998, 158 Pt 1, 1384-1387. [CrossRef]

15. Mannocci, A.; Di Thiene, D.; Del Cimmuto, A.; Masala, D.; Boccia, A.; De Vito, E.; La Torre, G. International Physical Activity Questionnaire: Validation and assessment in an Italian sample. Ital. J. Public Health 2010, 7, 369-376.

16. Gläser, S.; Obst, A.; Opitz, C.F.; Dörr, M.; Felix, S.B.; Empen, K.; Völzke, H.; Ewert, R.; Schäper, C.; Koch, B. Peripheral endothelial dysfunction is associated with gas exchange inefficiency in smokers. Respir. Res. 2011, 12, 53. [CrossRef] [PubMed]

17. Brischetto, M.J.; Millman, R.P.; Peterson, D.D.; Silage, D.A.; Pack, A.I. Effect of aging on ventilatory response to exercise and $\mathrm{CO}_{2}$. J. Appl. Physiol. 1984, 56, 1143-1150. [CrossRef] [PubMed]

18. McGurk, S.P.; Blanksby, B.A.; Anderson, M.J. The Relationship of Hypercapnic Ventilatory Responses to Age, Gender and Athleticism. Sports Med. 1995, 19, 173-183. [CrossRef]

19. Salazar-Martínez, E.; De Matos, T.R.; Arrans, P.; Santalla, A.; Orellana, J.N. Ventilatory efficiency response is unaffected by fitness level, ergometer type, age or body mass index in male athletes. Biol. Sport 2018, 35, 393-398. [CrossRef]

20. Cole, C.R.; Blackstone, E.H.; Pashkow, F.J.; Snader, C.E.; Lauer, M.S. Heart-Rate Recovery Immediately after Exercise as a Predictor of Mortality. N. Engl. J. Med. 1999, 341, 1351-1357. [CrossRef]

21. Crisafulli, E.; Scelfo, C.; Tzani, P.; Aiello, M.; Bertorelli, G.; Chetta, A. Asymptomatic peripheral artery disease can limit maximal exercise capacity in chronic obstructive pulmonary disease patients regardless of airflow obstruction and lung hyperinflation. Eur. J. Prev. Cardiol. 2017, 24, 990-999. [CrossRef] [PubMed]

22. Crisafulli, E.; Vigna, M.; Ielpo, A.; Tzani, P.; Mangia, A.; Teopompi, E.; Aiello, M.; Alfieri, V.; Bertorelli, G.; Palange, P.; et al. Heart rate recovery is associated with ventilatory constraints and excess ventilation during exercise in patients with chronic obstructive pulmonary disease. Eur. J. Prev. Cardiol. 2018, 25, 1667-1674. [CrossRef] [PubMed]

23. Gupta, A.; Madhavan, M.V.; Sehgal, K.; Nair, N.; Mahajan, S.; Sehrawat, T.S.; Bikdeli, B.; Ahluwalia, N.; Ausiello, J.C.; Wan, E.Y.; et al. Extrapulmonary manifestations of COVID-19. Nat. Med. 2020, 26, 1017-1032. [CrossRef] [PubMed] 